\title{
A Neural Network Algorithm to Detect Sulphur Dioxide Using IASI Measurements
}

\author{
Alessandro Piscini'1 , Elisa Carboni'², Fabio Del Frate ${ }^{3}$, Roy Gordon Grainger ${ }^{2}$ \\ ${ }^{1}$ Istituto Nazionale di Geofisica e Vulcanologia, Roma, Italy \\ ${ }^{2}$ COMET, Atmospheric, Oceanic and Planetary Physics, University of Oxford, Oxford, UK \\ ${ }^{3}$ Earth Observation Laboratory, Civil Engineering and Computer Science Engineering Department, \\ Tor Vergata University, Rome, Italy \\ Email: alessandro.piscini@ingv.it, elisa@atm.ox.ac.uk, delfrate@disp.uniroma2.it, r.grainger@physics.ox.ac.uk
}

Received 19 September 2014; revised 15 October 2014; accepted 10 November 2014

Copyright (C) 2014 by authors and Scientific Research Publishing Inc.

This work is licensed under the Creative Commons Attribution International License (CC BY).

http://creativecommons.org/licenses/by/4.0/

(c) (i) Open Access

\section{Abstract}

The remote sensing of volcanic sulphur dioxide $\left(\mathrm{SO}_{2}\right)$ is important because it is used as a proxy for volcanic ash, which is dangerous to aviation and is generally more difficult to discriminate. This paper presents an Artificial Neural Network (ANN) algorithm that recognizes volcanic $\mathrm{SO}_{2}$ in the atmosphere using hyperspectral remotely sensed data from the IASI instrument aboard the Metop-A satellite. The importance of this approach lies in exploiting all thermal infrared spectral information of IASI and its application to near real-time volcanic monitoring in a fast manner. In this paper, the ANN algorithm is demonstrated on data of the Eyjafjallajökull volcanic eruption (Iceland) during the months of April and May 2010, and on the Grímsvötn eruption occurring during May 2011. The algorithm consists of a two output neural network classifier trained with a time series consisting of some hyperspectral eruption datasets collected during 14 April to 14 May 2010 and a few from 22 to 26 May 2011. The inputs were all channels (441) in the IASI $v_{3}$ band and the target outputs (truth) were the corresponding retrievals of $\mathrm{SO}_{2}$ amount obtained with an optimal estimation method. The validation results for the Eyjafjallajökull independent data-sets had an overall accuracy of $100 \%$ and no commission errors, therefore demonstrating the feasibility of estimating the presence of $\mathrm{SO}_{2}$ using a neural network approach also a in cloudy sky conditions. Although the validation of the neural network classifier on datasets from the Grímsvötn eruption had no commission errors, the overall accuracies were lower due to the presence of omission errors. Statistical analysis revealed that those false negatives lie near the detection threshold for discriminating pixels affected by $\mathrm{SO}_{2}$. This demonstrated that the accuracy in classification is strictly related to the sensitivity of the model. The lower accuracy obtained in detecting $\mathrm{SO}_{2}$ for Grímsvötn validation dates might also be caused by less statistical knowledge of such an eruption during the training phase.

\section{Keywords}

Artificial Neural Networks, Pattern Recognition, Remote Sensing of Volcanoes, Volcano Monitoring, 


\section{Hyperspectral, Volcanic Sulphur Dioxide}

\section{Introduction}

Multi-layer perceptrons are used in many fields of science and technology. From the perspective of pattern recognition, they can be regarded as an extension of the many conventional statistical techniques which have been developed over several decades [1]. More extensive treatments of these topics can be found in the many textbooks on statistical pattern recognition, including [2]-[5]. Articles [6] and [7] have also emphasized the statistical underpinnings of neural networks.

The main application of ANN to remote sense data analysis is scene classification, more commonly land cover classification, namely the process in which pixels are grouped according to the similarities of their spectral properties. If a pixel satisfies a certain set of criteria then it is assigned to the land cover class that corresponds to those criteria. This is the most common task achieved with remote sensing, and applications that involve both supervised and unsupervised ANNs are numerous. Due to the absence of any assumption about the data, many land cover classifications use data from different sensors such as optical and radar data [8] [9], texture and ancillary data. Texture is incorporated in different ways: 1) precomputed per pixel texture information that is fed to the ANN together with the spectral information [10] or 2) incorporating neighbouring spectral information using a sliding window [11].

It was reported that ANNs have more accurate performance than other techniques such as statistical classifiers, especially when the functional space is particularly complex and the source of data presents different statistical distributions [12]-[15].

An additional advantage of the ANN approach is that they can perform supervised classification using fewer training data than those with maximum probability, because rules of recognition of a given category are based on the attributes, not only of training data of that particular category class, but also of other classes [16].

The IASI instrument is used for operational measurements of meteorological parameters for numerical weather prediction. However, the high density of spectral information available and good signal-to-noise characteristics mean that the instrument can also provide measurements of many chemical species. The high density of spectral information and low instrument noise means that IASI could potentially provide very sensitive detection of $\mathrm{SO}_{2}$, especially for plumes in the upper-troposphere and lower-stratosphere, where the thermal contrast with the layers below is maximized. Usually full retrievals are time-consuming when searching for a sporadic event such as a volcanic eruption within a large data set. Detection methods do not require on-line radiative transfer calculations and can therefore be used to provide atmospheric measurements quickly, for example to help with volcanic hazard avoidance.

A commonly used method for the fast detection of trace atmospheric species is to calculate the difference in brightness temperature (BTD) between a small number of channels which are sensitive to the target species and others which are insensitive. The BTD between channels is then compared against a threshold which indicates a positive detection.

Simple BTD filters for the detection of $\mathrm{SO}_{2}$ are applied operationally to provide an early warning of volcanic activity and to help track volcanic plumes in near-real-time [17]-[19]. Although fast and robust, current BTD methods do not fully exploit the spectral range and resolution of hyperspectral instruments, and the noise associated with the measurements remains high. $\mathrm{SO}_{2}$ can be tracked from IASI using the difference in signal between two channels located at 1371.50 and $1371.75 \mathrm{~cm}^{-1}$ in the $\mathrm{SO}_{2} v_{3}$ vibrational band and two background channels at 1407.25 and $1408.75 \mathrm{~cm}^{-1}$ outside the $\mathrm{SO}_{2}$ band [20]. Recently the detection method of Walker [21], uses channels between 1300 and $1410 \mathrm{~cm}^{-1}$ (441 channels). It is a fast method which uses many spectral channels to separate the contribution of $\mathrm{SO}_{2}$ from the contribution of other parameters affecting the measurement.

To date, no significant studies involving volcanic $\mathrm{SO}_{2}$ detection using ANNs have been carried out. The main aim of this study is to verify if such a technique may be useful and give substantial improvements for real time monitoring of $\mathrm{SO}_{2}$, representing a reliable ANN monitoring tool during preliminary detection phase.

The challenge was to assess a classification problem by using ANN in order to detect the presence in the atmosphere of volcanic $\mathrm{SO}_{2}$ using IASI hyperspectral data as input and the corresponding $\mathrm{SO}_{2}$ retrievals by [22] 
as target outputs.

Beside its fast usage in the real time application, the advantage of ANN approach is in the ability to model the non-linearity in the variable space and in exploiting all the spectral information contained in hyperspectral data, and it does not need to select any target and background channels for implementing detection filters.

In this study, we first provide in Section 2.1. an overview of the IASI sensor characteristics and description of $\mathrm{SO}_{2}$ total column estimation (Section 2.2.), then we discuss the neural network approach for $\mathrm{SO}_{2}$ detection (Section 2.3.). In Section 3, the scenario where the ANN approach has been applied is introduced and the results obtained are discussed. Finally the conclusions are reported in Section 4.

\section{Neural Network-Based Classifier Algorithm}

The neural network must first be "trained" by having it process a large number of input patterns and their associated reference output patterns. Once trained, the neural network is able to recognize similarities when presented with a new input pattern, resulting in a predicted output pattern [23].

\subsection{Metop-IASI Instrument}

The IASI sensor is onboard Metop-A, a European weather satellite in operation since 2007. IASI is a Fourier transform spectrometer that covers the spectral range $645-2760 \mathrm{~cm}^{-1}$ (3.62 to $\left.15.5 \mu \mathrm{m}\right)$ with spectral sampling of $0.25 \mathrm{~cm}^{-1}$ and spectral resolution of $0.5 \mathrm{~cm}^{-1}$ [24]. It has a nominal radiometric accuracy of $0.25-0.58 \mathrm{~K}$. The field-of-view (FOV) consists of four circular footprints of 12 diameter (at nadir) inside a square of $50 \times 50$ $\mathrm{km}$, step-scanned across tracks (30 steps). It has a $2000 \mathrm{~km}$ wide swath and nominally can achieve global coverage in $12 \mathrm{~h}$.

\section{2. $\mathrm{SO}_{2}$ Total Column Content Description}

Values used here as target outputs were obtained with the Optimal Estimation scheme to retrieve $\mathrm{SO}_{2}$ column amount and altitude from nadir satellite TIR measurements using the two $\mathrm{SO}_{2}$ absorption bands centred at about 8.7 and $7.3 \mu \mathrm{m}$, the $v_{1}$ and $v_{3}$ bands respectively; more details of the retrieval are in [22]. This retrieval technique uses an error covariance matrix based on an $\mathrm{SO}_{2}$-free climatology of differences between the IASI measurements and forward modelled spectra. Any differences not related to $\mathrm{SO}_{2}$ between IASI spectra and those simulated by a forward model are included in the covariance matrix, allowing a comprehensive error budget to be computed for every pixel.

As IASI measures atmospheric emission, it provides continuous measurements throughout an orbit. The IASI retrieval follows the method of [22] where $\mathrm{SO}_{2}$ concentration is modelled by a Gaussian profile. The optimal estimation technique of [25] is then used to estimate $\mathrm{SO}_{2}$ column amount and the height of the $\mathrm{SO}_{2}$ profile, and the surface skin temperature using IASI measurements from 1000 to $1200 \mathrm{~cm}^{-1}$ and from 1300 to $1410 \mathrm{~cm}^{-1}$ (the $v_{1}$ and $v_{3} \mathrm{SO}_{2}$ bands).

\subsection{Neural Network Methodology}

In this work, Backpropagation Neural Networks (BPNN) have been used. These networks are the most widely used type for their flexibility and adaptability to model a wide spectrum of problems in many application areas [26].

A neural network for $\mathrm{SO}_{2}$ detection was implemented using a training set of 59 IASI datasets, spanning the April-May 2010 Eyjafjallajökull and May 2011 Grímsvötn eruptions (Iceland). The training sets used IASI retrievals from [22] as representative of $\mathrm{SO}_{2}$ class.

The total number of training samples was 74,614, of which 43,437 were classified as $\mathrm{SO}_{2}$ affected of which $84 \%$ belong to the Eyjafjallajökull eruption.

The network topology consists of 441 inputs, namely the brightness temperatures in the $1300-1410 \mathrm{~cm}^{-1}$ channels, the so-called $v_{3}$ band, comprising the range of wavelengths containing information used for $\mathrm{SO}_{2}$ amount estimation. Ten neurons were used in a single hidden layer, in order to cope with non linearly discrete problems [23]. Finally, outputs consisted of the two possible classification results, namely " $\mathrm{SO}_{2}$ " and "not $\mathrm{SO}_{2}$ ".

When training a neural network, it is of interest to obtain a network with an optimal generalization performance, i.e. the network performance should not degrade significantly when datasets other than the training 
one are analyzed.

Standard neural network architectures, like the fully connected multi layer perceptron, generally have too large a parameter space, and are prone to over-fitting [27]. During the training phase, although the network performance appears to constantly improve on the training sets, at some point it actually begins to worsen in terms of errors on unseen datasets. During supervised training of the neural network, cross validation can be used to detect when overfitting starts: training can then stopped before convergence to avoid overfitting, a process called early stopping [28].

In this study, early stopping was carried out by splitting the training data into three sets: a training set, a cross validation set and a test set. These consisted respectively of $70 \%, 20 \%$ and $10 \%$ of the total number of training samples. The first set was used for network training. The cross validation set, consisting of $20 \%$, was analyzed at a predefined number of epochs, to assess performance on datasets other than the training one. Finally, the test set $(10 \%)$ was used as an independent data source to assess network performance after the training phase. The result obtained by processing $10 \%$ of the samples belonging to the test set, but not used for training, showed an overall accuracy of $100 \%$ without omission (false negatives) or commission (false positive) errors. The samples were 4092 pixels with $\mathrm{SO}_{2}$ and 1309 without, respectively.

\section{Application to Two Operational Scenarios}

After completion of the training process, the ANN classifier algorithm has been proposed for a remote sensing application such as the monitoring of two volcanic eruptions that occurred in Iceland in 2010 and 2011. The 14 April to 24 May 2010 Eyjafjallajökull eruption caused widespread impacts [29].

It was an explosive eruption with an injection of volcanic ash into the atmosphere and plumes that affected many regions of Europe. Plumes reached altitudes of $9 \mathrm{~km}$, and the ash was transported across Europe and to the Atlantic Ocean. Despite its impact, the explosive phase was modest in size and the amount of $\mathrm{SO}_{2}$ released was low.

The Grímsvötn eruption occurred from May 21 to May 23 2011. It injected into the atmosphere a higher concentration of $\mathrm{SO}_{2}$ than Eyjafjallajökull. The height reached by the plume was $20 \mathrm{~km}$ [30].

In order to evaluate the performance of neural network classifier in terms of its generalization capability and accuracy in detecting $\mathrm{SO}_{2}$ presence in the atmosphere from IASI datasets, we applied the trained ANN classifier to two independent IASI datasets from the May 2010 Eyjafjallajökull eruption and to two independent IASI datasets from the Grímsvötn eruption which occurred the following year. Note that ANN has been validated on datasets which include all IASI orbits, not only on $\mathrm{SO}_{2}$ plume data, with a significant number of pixels not affected by $\mathrm{SO}_{2}$ (more than $40 \%$ ). Performance was assessed in terms of overall accuracy and Producer accuracy. The former represents the percentage of correct classifications, with respect to the total number of pixels analysed, considering all classes (i.e. $\mathrm{SO}_{2}$ and not $\mathrm{SO}_{2}$ ). The Producer accuracy instead represents the percentage of correct classifications with respect to the total obtained for that output class and it is an omission error indicator.

Tables 1-4 describe the confusion matrices obtained by applying the NN classifier to these independent datasets. Figures 1-4 show comparisons between classification maps obtained from the ANN classifier and from the $\mathrm{SO}_{2}$ retrieved by Carboni [22] for all validation dates.

In Table 1, Table 2, which summarize the results related to the Eyjafjallajökull eruptions of April 302010 and May 15 2010, the neural network classifier achieves an accuracy of $100 \%$. This is a very good result, considering the ANN classifier has been applied to the entire IASI orbits. In fact, looking at Figure 1, despite most of the pixels not being affected by $\mathrm{SO}_{2}$, the ANN classifier perfectly detects $\mathrm{SO}_{2}$ plume. The same result is obtained when ANN is applied to May 2010 (Figure 2). Table 2 describes the confusion matrix and shows an overall accuracy of $100 \%$ for detecting the plume, despite the fact that it extends from $45^{\circ}$ to $75^{\circ} \mathrm{N}$. Again, neither commission nor omission errors are present.

The results of applying the ANN classifier to the IASI datasets during the Grímsvötn eruption are described by confusion matrices depicted in Table 3 and Table 4 and depicted in Figure 3 and Figure 4, for May, 22 2011, at 12:00 and 20:00 UTC, respectively.

In the case of the morning orbit depicted in Table 3, the overall accuracy obtained is $99.1 \%$. The producer accuracy, which measures the probability that the classifier correctly labels a pixel as $\mathrm{SO}_{2}$, is $70.3 \%$. The lower accuracy obtained is due to the presence of an omission error, because $29.7 \%$ of pixels with $\mathrm{SO}_{2}$ have been 
Table 1. Eyjafjallajökull. Confusion matrix assessing the classification accuracy on the IASI validation date of April 30, 2010, afternoon orbit.

\begin{tabular}{ccccc}
\hline 30 April 2010 & & $\mathrm{SO}_{2}$ & \multicolumn{2}{c}{ Prod. Acc. } \\
\hline Overall Acc.: $100 \%$ & & Yes & No & $(\%)$ \\
$\mathrm{NN}$ & Yes & 161 & 0 & 100.0 \\
& No & 0 & 19,139 & 100.0 \\
\hline
\end{tabular}

Table 2. Eyjafjallajökull. Confusion matrix assessing the classification accuracy on the IASI validation date of May 15, 2010, morning orbit.

\begin{tabular}{ccccc}
\hline 15 May 2010 & & $\mathrm{SO}_{2}$ & Prod. Acc. \\
\hline Overall Acc.: $100 \%$ & & Yes & No & $(\%)$ \\
$\mathrm{NN}$ & Yes & 1823 & 0 & 100.0 \\
& No & 0 & 37,180 & 100.0 \\
\hline
\end{tabular}

Table 3. Grímsvötn. Confusion matrix assessing the classification accuracy on the IASI validation date of May 22, 2011, 12:00 UTC.

\begin{tabular}{ccccc}
\hline 22 May 2011, 12:00 UTC & & $\mathrm{SO}_{2}$ & Prod. Acc. \\
\hline Overall Acc.: 99.1\% & & Yes & No & (\%) \\
NN & Yes & 298 & 0 & 70.3 \\
& No & 126 & 13,865 & 100.0 \\
\hline
\end{tabular}

Table 4. Grímsvötn. Confusion matrix assessing the classification accuracy on the IASI validation date of May 22, 2011, 20:00 UTC.

\begin{tabular}{ccccc}
\hline 22 May 2011, 20:00 UTC & & $\mathrm{SO}_{2}$ & Prod. Acc. \\
\hline Overall Acc.: 98.5\% & & Yes & No & $(\%)$ \\
NN & Yes & 236 & 0 & 57.0 \\
& No & 178 & 11,653 & 100.0 \\
\hline
\end{tabular}

labelled as not affected by $\mathrm{SO}_{2}$.

Looking at the histograms in Figure 5 (top), representing the statistical distribution of false negatives for the 22 May 2011 date, we notice that most of the false negatives have values lower than $3 \mathrm{DU}$, which is around the $\mathrm{SO}_{2}$ detection threshold for a plume height between 2 and $4 \mathrm{~km}$ [21]. Looking at the maps depicted in Figure 6 we notice that they belong to a portion of the plume located close to the vent and are characterized by a height of between $2-4 \mathrm{~km}$ [30]. Considering that the $\mathrm{SO}_{2}$ detection threshold at these altitudes is $3.3 \mathrm{DU}$, we can assert that the ANN classifier shows a sensitivity in accord with the model for low $\mathrm{SO}_{2}$ amounts in the lower troposphere. Furthermore it puts in evidence the absorption band limit at $7.3 \mu \mathrm{m}$ when observing $\mathrm{SO}_{2}$ in low troposhere.

For total $\mathrm{SO}_{2}$ column amounts of less than $0.2 \mathrm{DU}$ concentrated in the boundary layer between $0-2 \mathrm{~km}$ the signal falls below the noise level of the instrument [21]. Instead, when $\mathrm{SO}_{2}$ is higher into the atmosphere due to an explosive volcanic event it is possible to discern very low concentrations. As shown in Figure 7, showing only positive detections for both Grímsvötn validation's datasets, ANN classifier well detect low amount of $\mathrm{SO}_{2}$ when they are located at higher altitudes (low stratosphere) [30].

The same assertion can be made for the afternoon orbit of the May, 22, 2011, 20:00 UTC: looking at Table 4, an overall accuracy of $98.5 \%$ is shown. Producer accuracy is $57 \%$ and, once again, this is due to false negatives related to pixels of plume at lower altitudes, as in the previous validation. In fact, looking at the histogram representing $\mathrm{SO}_{2}$ distribution (Figure 5, bottom) most of the values are around the detection threshold used for $\mathrm{SO}_{2}$ discrimination, but not higher than $3 \mathrm{DU}$, which characterizes the detection threshold for the part of the plume in the lower troposphere. Instead, when $\mathrm{SO}_{2}$ is higher into the atmosphere due to an explosive volcanic event it may be possible to discern very low concentrations.

The retrieval methodology of [22] establishes that for measurements in the thermal infrared spectral range the sensitivity is better for plume injected at high altitudes where the air is colder and the thermal contrast is higher, 

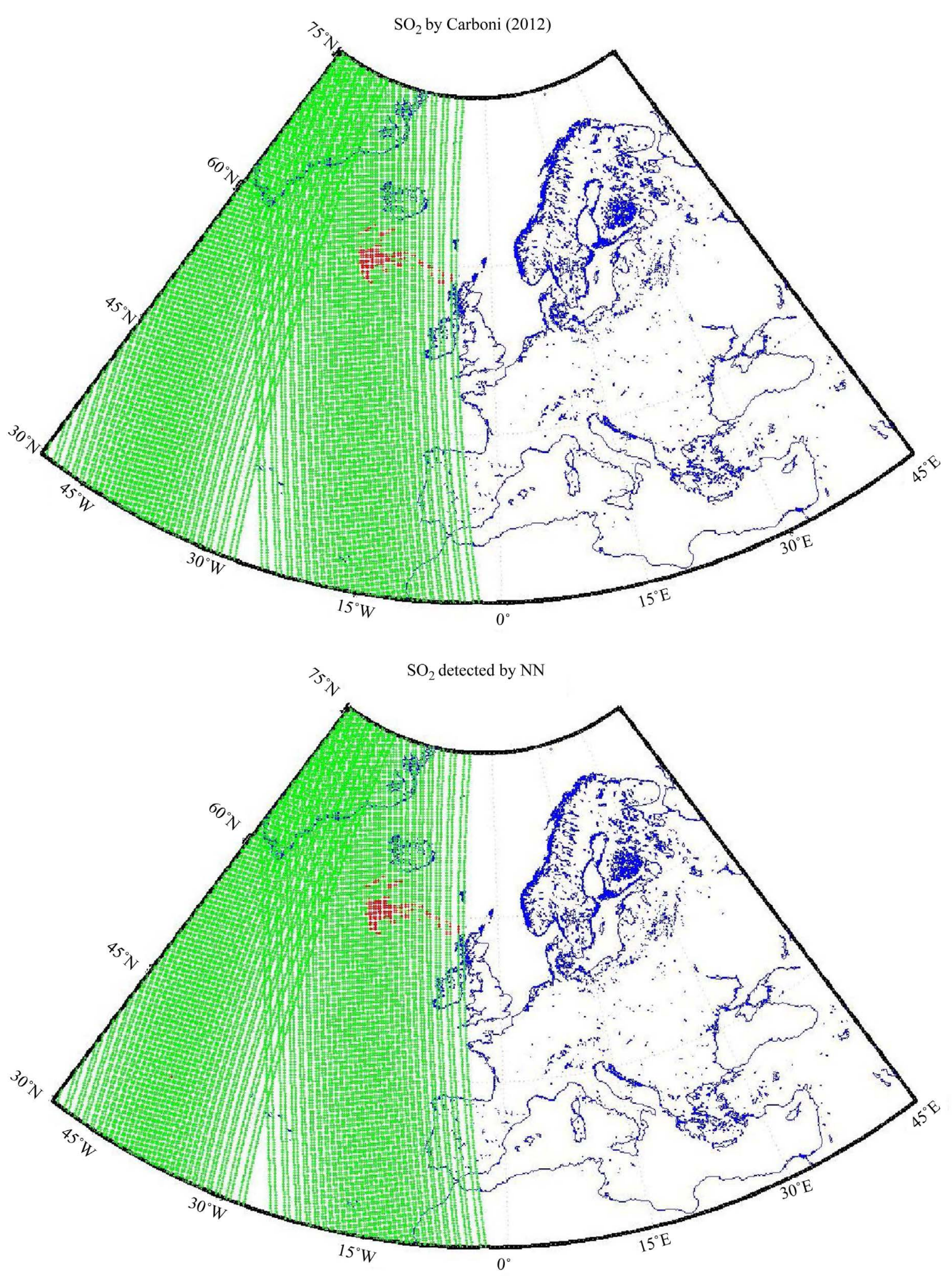

Figure 1. Comparison between $\mathrm{SO}_{2}$ retrieved by Carboni [22] (top) and $\mathrm{SO}_{2}$ map from $\mathrm{ANN}$ classifier (bottom) for Eyjafjallajökull April 30, 2010 afternoon orbit. Pixels affected by $\mathrm{SO}_{2}$ are coloured red, pixels not affected by $\mathrm{SO}_{2}$ are coloured green. 

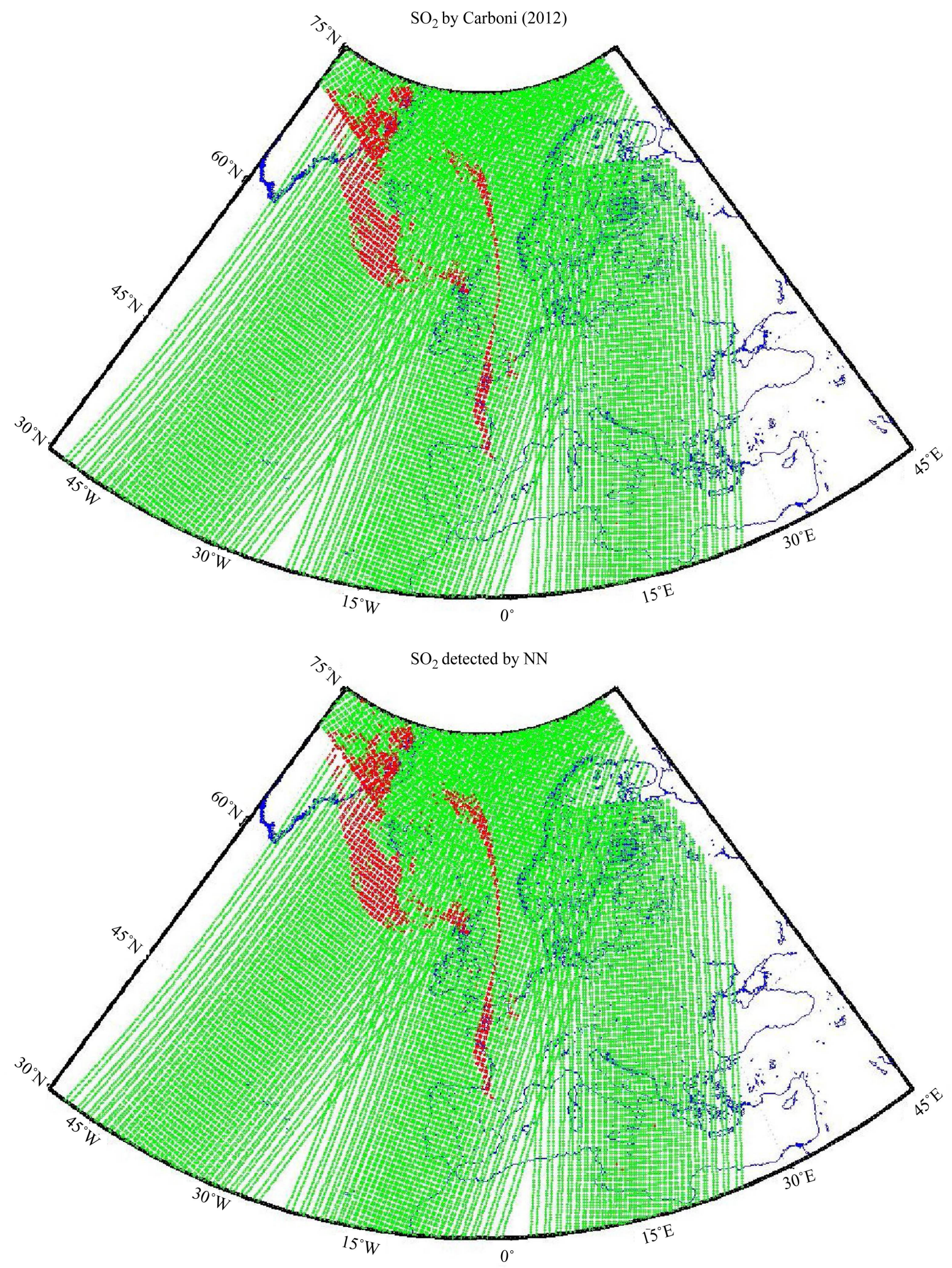

Figure 2. Comparison between $\mathrm{SO}_{2}$ retrieved by Carboni [22] (top) and $\mathrm{SO}_{2}$ map from ANN classifier (bottom) for Eyjafjallajökull May 15, 2010 morning orbit. Pixels affected by $\mathrm{SO}_{2}$ are coloured red, pixels not affected by $\mathrm{SO}_{2}$ are coloured green. 

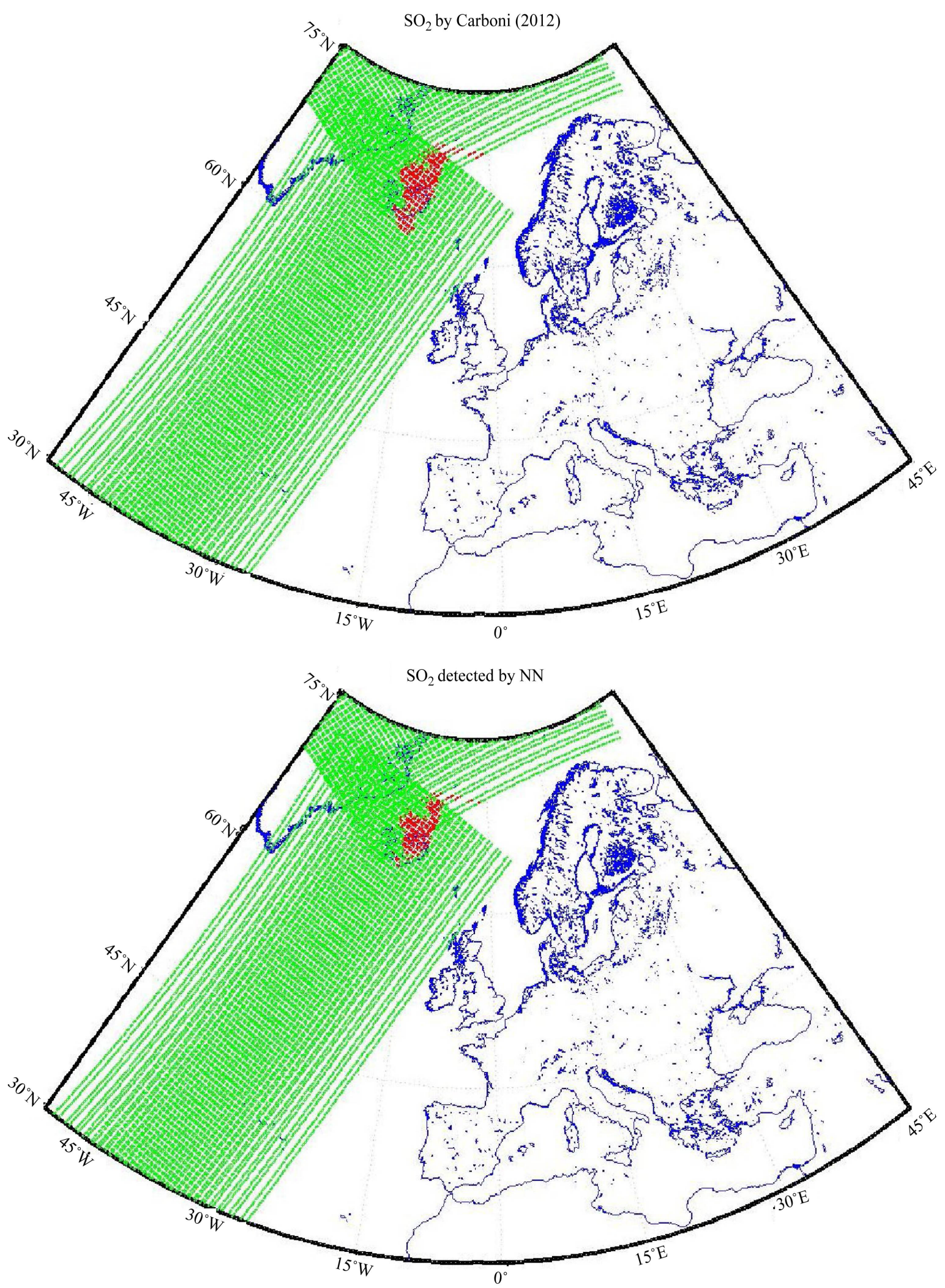

Figure 3. Comparison between $\mathrm{SO}_{2}$ retrieved by Carboni [22] (top) and $\mathrm{SO}_{2}$ map from ANN classifier (bottom) for Grímsvötn May 22, 2011, 12:00 UTC. Pixels affected by $\mathrm{SO}_{2}$ are coloured red, pixels not affected by $\mathrm{SO}_{2}$ are coloured green. 

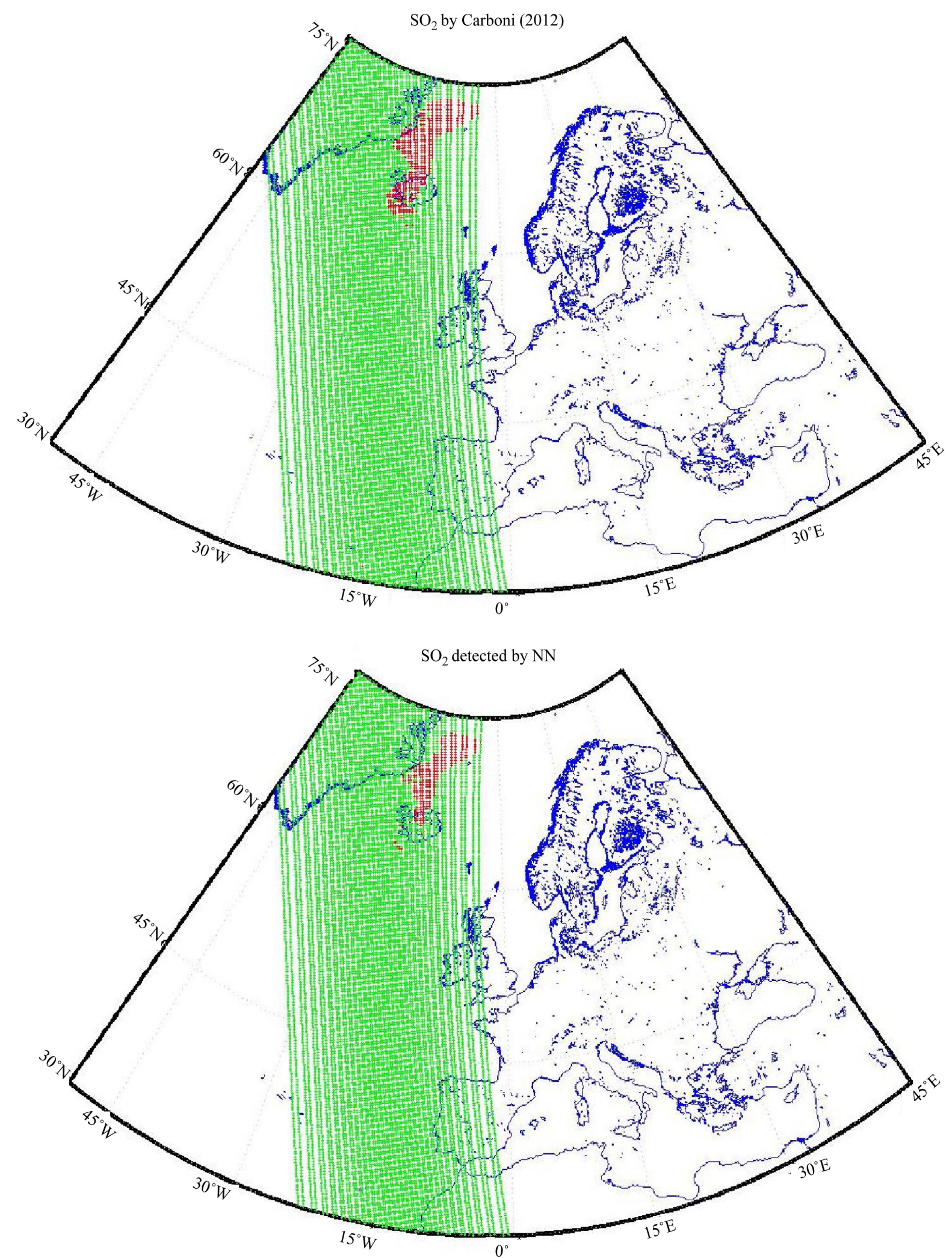

Figure 4. Comparison between $\mathrm{SO}_{2}$ retrieved by Carboni [22] (top) and $\mathrm{SO}_{2}$ map from ANN classifier (bottom) for Grímsvötn May 22, 2011, 12:00 UTC. Pixels affected by $\mathrm{SO}_{2}$ are coloured red, pixels not affected by $\mathrm{SO}_{2}$ are coloured green. 
w.

u. 

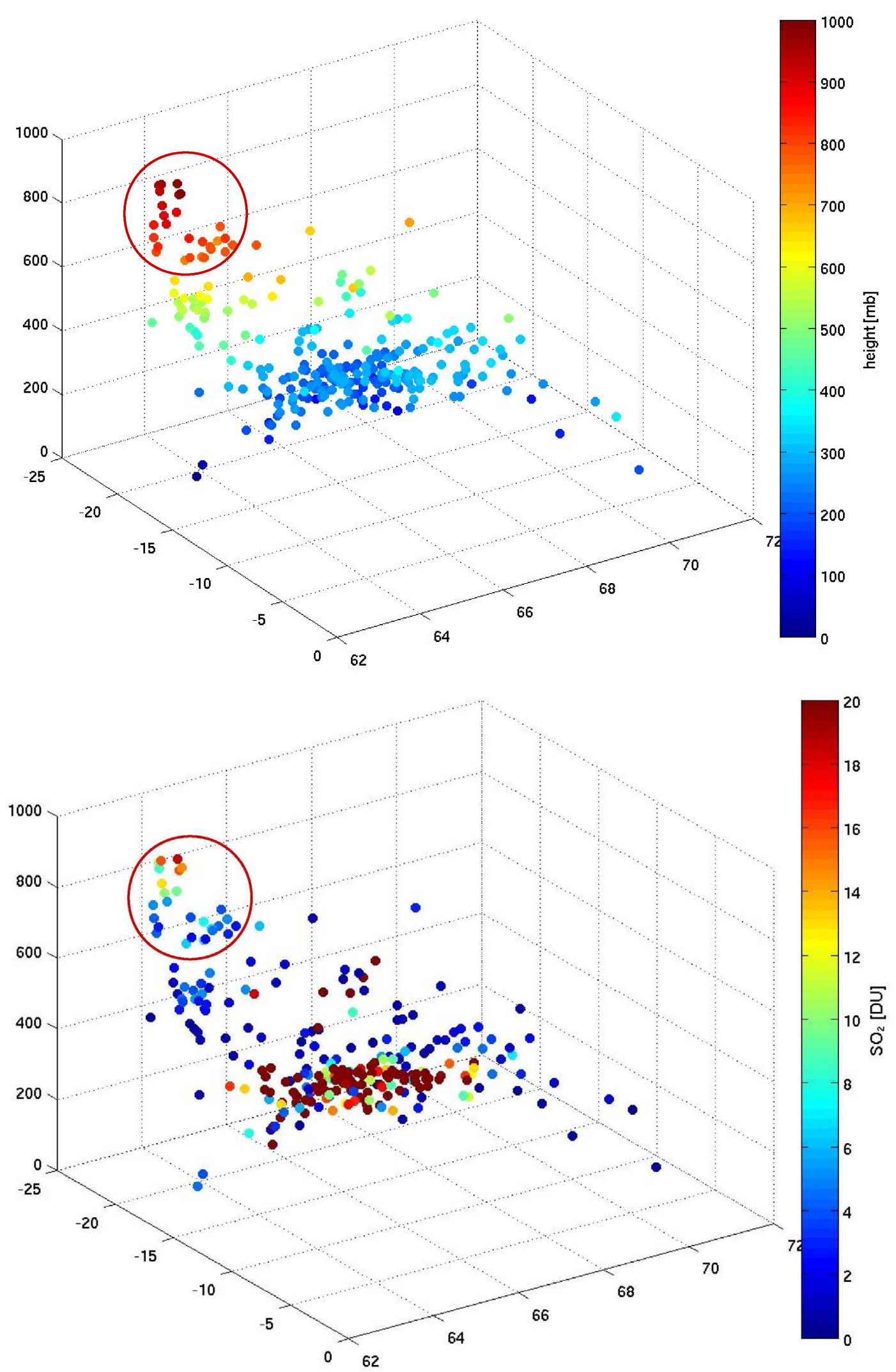

Figure 6. Grímsvötn May 22, 2011, 12:00 UTC. $\mathrm{SO}_{2}$ Cloud height in mb (top) and $\mathrm{SO}_{2}$ amount in DU (bottom). 

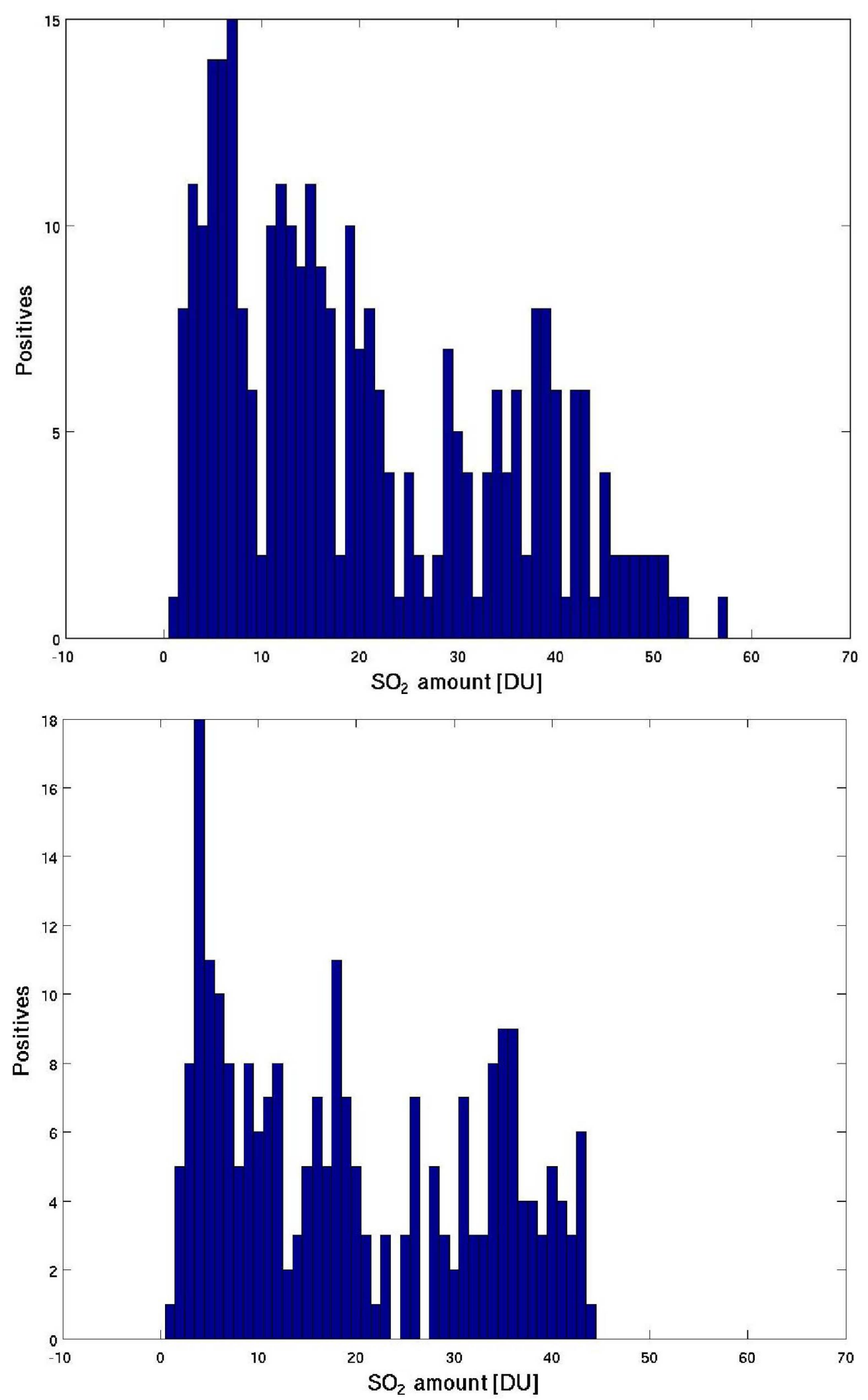

Figure 7. $\mathrm{SO}_{2}$ amount distribution in DU considering only positive detections, for Grímsvötn May 22, 2011, 12:00 UTC (top) and May 22, 2011, 20:00 UTC (botttom). 
while at lower altitudes (e.g. the troposphere) the lower thermal contrast reduces the sensitivity of the detection method, so we can assert that the ANN classifier is in accord with the sensitivity of the model.

What can be underlined is that no commission errors are present at the validation stage (pixels erroneously labelled as affected by $\mathrm{SO}_{2}$ ) for both 2010 and 2011 eruptions, and the method shows the same accuracy when applied to IASI images with different illumination conditions (morning and afternoon orbits) and in cloudy sky conditions. Furthermore, it is noticeable that most of the training samples are from the Eyjafjallajökull eruption and only a low percentage from the Grímsvötn one (26\%), which represents an event statistically not well known at the training stage. This can explain why the ANN classifier reveals a loss of accuracy when applied to Grímsvötn eruption.

\section{Conclusions}

This work proves the detection capability of volcanic $\mathrm{SO}_{2}$ by means of an algorithm neural network based classifier, applied to the thermal channels of the IASI hyperspectral sensor. $\mathrm{SO}_{2}$ amounts estimated by [22] were used as training target outputs.

The resulting confusion matrices associated with application to independent datasets spanning two Eyjafjallajökull volcanic eruptions revealed an accuracy of $100 \%$ on both tested images.

The results of applying the ANN classifier to the Grímsvötn eruption reveals an accuracy lower in detecting $\mathrm{SO}_{2}$ plume, but these cases included: a) The data-sets belonging to the Grímsvötn eruption represented a minor percentage of IASI time-series used as training samples; b) the presence of false negatives, i.e. pixels affected by $\mathrm{SO}_{2}$ not detected. In this case an analysis carried out on false negatives for both validation dates revealed that those pixel belonged to the portion of the plume at tropospheric altitudes where the sensitivity of the method is lower.

Nevertheless, the neural network classifier has been shown to work well both on daytime and night-time images and in cloudy sky conditions, and it successfully overcame the detection of false positives present in the validation dataset images, whose presence in multispectral or hyperspectral images can often undermine the performance of traditional classification algorithms. Therefore the proposed method represents a reliable new approach for volcanic $\mathrm{SO}_{2}$ detection and demonstrates also its usefulness in near real time volcanic monitoring activities, due to its fast application in the operational stage.

\section{References}

[1] Bishop, C.M. (1995) Neural Networks for Pattern Recognition. Oxford University Press, New York.

[2] Duda, R.O. and Hart, P.E. (1973) Pattern Classification and Scene Analysis. John Wiley, New York.

[3] Hand, D.J. (1981) Pattern Recognition: A Statistical Approach. John Wiley, New York.

[4] Devijver, P.A. and Kittler, J. (1982) Discrimination and Classification. Prentice-Hall, Englewood Cliffs.

[5] Fukunaga, K. (1990) Introduction to Statistical Pattern Recognition. Second Edition, Academic Press, San Diego.

[6] Ripley, B.D. (1994) Neural Networks and Related Methods for Classification. Journal of the Royal Statistical Society: Series B, 56, 409-456.

[7] Cheng, B. and Titterington, D.M. (1994) Neural Networks: A Review from a Statistical Perspective. Statistical Science, 9, 254.

[8] Benediktsson, J.A. and Sveinsson, J.R. (1997) Feature Extraction for Multisource Data Classification with Artificial Neural Networks. International Journal of Remote Sensing, 18, 727-740. http://dx.doi.org/10.1080/014311697218728

[9] Augusteijn, M.F. and Warrender, C.E. (1998) Wetland Classification Using Optical and Radar Data and Neural Network Classification. International Journal of Remote Sensing, 19, 1545-1560. http://dx.doi.org/10.1080/014311698215342

[10] Lloyd, C.D., Berberoglu, S., Curran, P.J., and Atkinson, P.M. (2004) Wetland Classification Using Optical and Radar Data and Neural Network Classification. International Journal of Remote Sensing, 25, 3943-3965. http://dx.doi.org/10.1080/0143116042000192321

[11] Kurnaz, M.N., Dokur, Z. and Olmez, T. (2005) Segmentation of Remote-Sensing Images by Incremental Neural Network. Pattern Recognition Letters, 26, 1096-1104. http://dx.doi.org/10.1016/j.patrec.2004.10.004

[12] Benediktsson, J.A., Swain, P.H. and Ersoy, O.K. (1990) Neural Network Approaches versus Statistical Methods in Classification of Multisource Remote Sensing Data. IEEE Transactions on Geoscience and Remote Sensing, 28, 540551. http://dx.doi.org/10.1109/TGRS.1990.572944 
[13] Benediktsson, J.A., Swain, P.H. and Ersoy, O.K. (1993) Conjugate Gradient Neural Networks in Classification of Multisource and Very High Dimensional Remote Sensing Data. International Journal of Remote Sensing, 14, 2883-2903. http://dx.doi.org/10.1080/01431169308904316

[14] Schalkoff, R. (1992) Neural Networks for Pattern Recognition. Oxford University Press, New York.

[15] Pacifici, F., Del Frate, F., Emery, W.J., Gamba, P. and Chanussot, J. (2008) Urban Mapping Using Coarse SAR and Optical Data: Outcome of the 2007 GRS-S Data Fusion Contest. IEEE Geoscience and Remote Sensing Letters, 5, 331335. http://dx.doi.org/10.1109/LGRS.2008.915939

[16] Paola, J.D. and Schowengerdt, R.A. (1995) A Detailed Comparison of Backpropagation Neural Network and Maximum-Likelihood Classifiers for Urban Land Use Classification. IEEE Transactions on Geoscience and Remote Sensing, 33, 981-996. http://dx.doi.org/10.1109/36.406684

[17] Rix, M., Valks, P., Hao, N., van Geffen, J., Clerbaux, C., Clarisse, L. and Coheur, P.F. (2009) Satellite Monitoring of Volcanic Sulfur Dioxide Emissions for Early Warning of Volcanic Hazards. IEEE Journal of Selected Topics in Applied Earth Observations and Remote Sensing, 2, 196-206.

[18] van Geffen, J., Van Roozendael, M., van Gent, J., Valks, P. and Rix, M. (2009) An Alert System for Volcanic $\mathrm{SO}_{2}$ Emissions Using Satellite Measurements. Proceedings of the 2009 EUMETSAT Meteorological Satellite Conference, Bath, 21-25 September 2009, 55.

[19] Prata, A. (2009) Satellite Detection of Hazardous Volcanic Clouds and the Risk to Global Air Traffic. Natural Hazards, 51, 303-324. http://dx.doi.org/10.1007/s11069-008-9273-z

[20] Clarisse, L., Coheur, P.F., Prata, A.J., Hurtmans, D., Razavi, A., Phulpin, T., Hadji-Lazaro, J. and Clerbaux, C. (2008) Tracking and Quantifying Volcanic $\mathrm{SO}_{2}$ with IASI, the September 2007 Eruption at Jebel at Tair. Atmospheric Chemistry and Physics, 8, 7723-7734. http://dx.doi.org/10.5194/acp-8-7723-2008

[21] Walker, J.C., Carboni, E., Dudhia, A. and Grainger, R.G. (2012) Improved Detection of Sulphur Dioxide in Volcanic Plumes Using Satellite-Based Hyperspectral Infra-Red Measurements: Application to the Eyjafjallajökull 2010 Eruption. Journal of Geophysical Research: Atmospheres, 117. http://dx.doi.org/10.1029/2011JD016810

[22] Carboni, E., Grainger, R., Walker, J., Dudhia, A. and Siddans, R. (2012) A New Scheme for Sulphur Dioxide Retrieval from IASI Measurements: Application to the Eyjafjallajökull Eruption of April and May 2010. Atmospheric Chemistry and Physics, 12, 11417-11434. http://dx.doi.org/10.5194/acp-12-11417-2012

[23] Hecht-Nielsen, R. (1990) Neurocomputing. Addison-Wesley, Reading.

[24] Blumstein, D., Chalon, G., Carlier, T., Buil, C., Hebert, P., Maciaszek, T., Ponce, G., Phulpin, T., Tournier, B., Simeoni, D., Astruc, P., Clauss, A., Kayal, G. and Jegou, R. (2004) IASI Instrument: Technical Overview and Measured Performances. SPIE Proceedings, 5543, 196-207.

[25] Rodgers, C.D. (2000) Inverse Methods for Atmospheric Sounding: Theory and Practice. World Scientific, River Edge.

[26] Rumelhart, D.E., Durbin, R., Golden, R. and Chauvin, Y. (1995) Backpropagation: The Basic Theory. In: Rumelhart, D.E. and Yves, C., Eds., Backpropagation: Theory, Architecture, and Applications, Lawrence Erlbaum, Mahwah, 1-34.

[27] Geman, S., Bienenstock, E. and Doursat, R. (1992) Neural Networks and the Bias/Variance Dilemma. Neural Computation, 4, 1-58. http://dx.doi.org/10.1162/neco.1992.4.1.1

[28] Prechelt, L. (1998) Automatic Early Stopping Using Cross Validation: Quantifying the Criteria. Neural Networks, 11, 761-767. http://dx.doi.org/10.1016/S0893-6080(98)00010-0

[29] Zehner, C. (2010) Monitoring Volcanic Ash from Space. Proceedings of the ESA-EUMETSAT Workshop on the 14 April to 23 May 2010 Eruption at the Eyjafjoll Volcano, South Iceland. Frascati, 26-27 May 2010.

[30] Piscini, A., Carboni, E., Del Frate, F. and Grainger, R.G. (2014) Simultaneous Retrieval of Volcanic Sulphur Dioxide and Plume Height from Hyperspectral Data Using Artificial Neural Networks. Geophysical Journal International, 198, 697-709. http://dx.doi.org/10.1093/gii/ggu152 
Scientific Research Publishing (SCIRP) is one of the largest Open Access journal publishers. It is currently publishing more than 200 open access, online, peer-reviewed journals covering a wide range of academic disciplines. SCIRP serves the worldwide academic communities and contributes to the progress and application of science with its publication.

Other selected journals from SCIRP are listed as below. Submit your manuscript to us via either submit@scirp.org or Online Submission Portal.
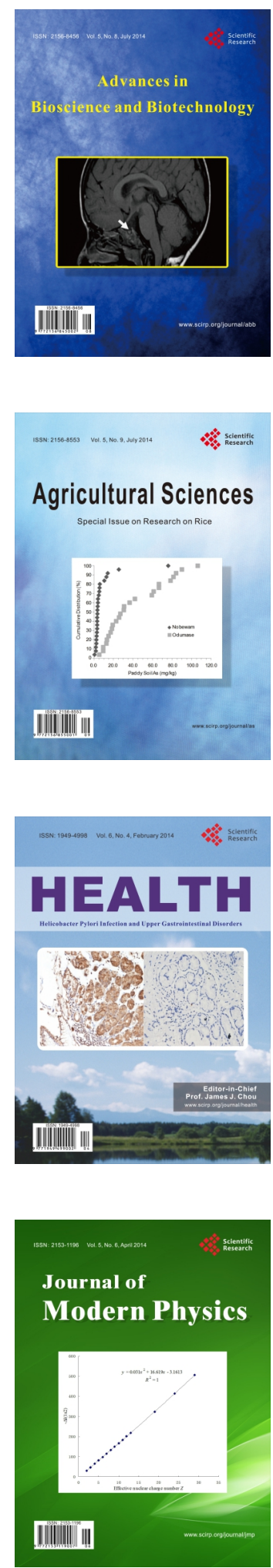
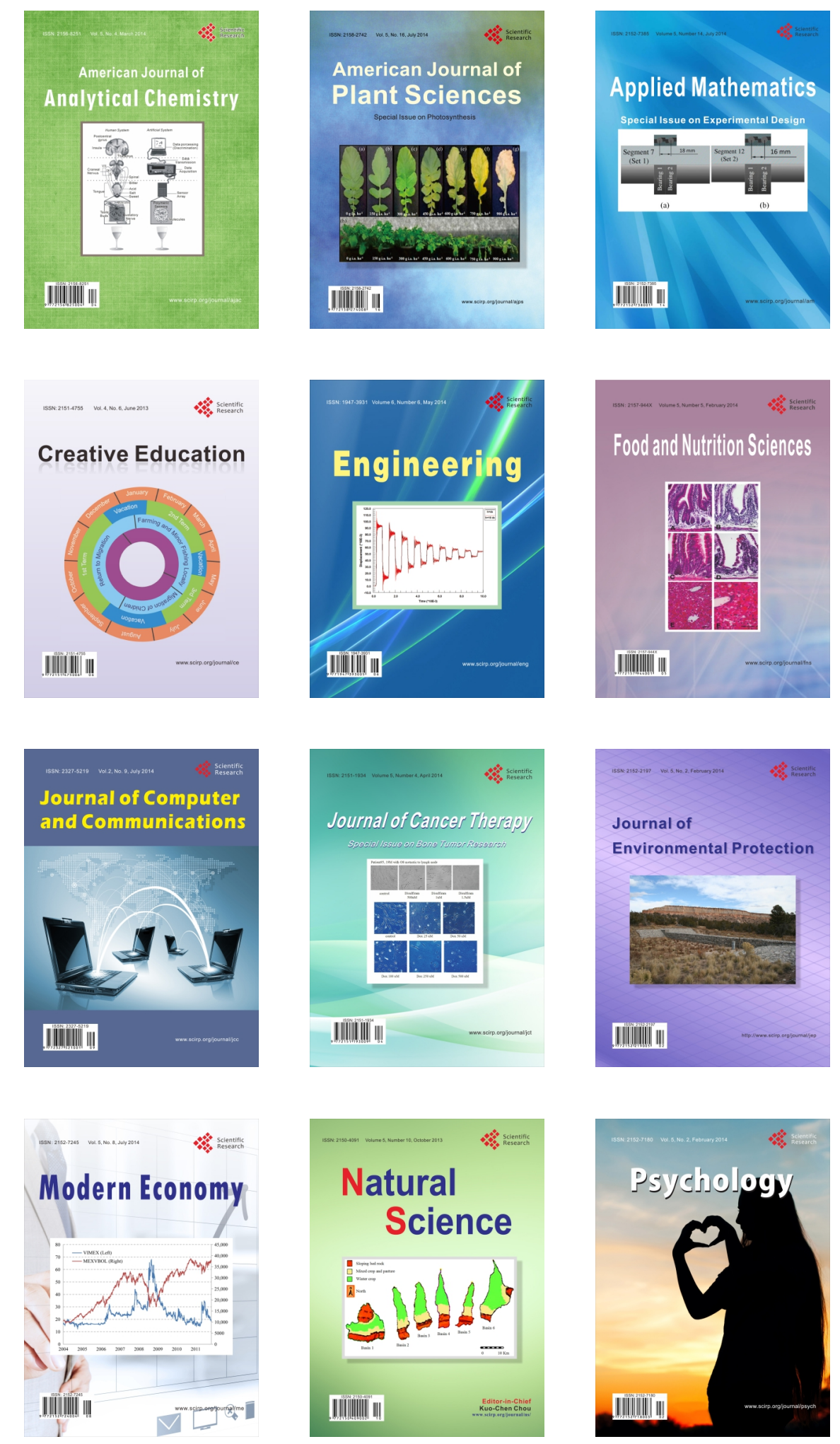